V, 13, n. 1, 2017.

\title{
DIÁLOGOS ENTRE EDUCAÇÃO E POLÍTICA: O ensino primário nas mensagens dos Governadores de Goiás. (1946-1961)
}

\author{
Maria Aparecida Alves Silva. Universidade Federal de Uberlândia/doutoranda em Educação \\ - mariazinharv@hotmail.com \\ Kênia Guimarães Furquim Camargo. Pontifícia Universidade Católica de Goiás - \\ keniafurquim2@hotmail.com
}

\begin{abstract}
RESUMO: O presente estudo tem como objetivo principal analisar a organização e estrutura do ensino primário, no período de 1946 a 1961, a partir das mensagens dos governadores goianos. Tratase de uma pesquisa qualitativa, de cunho documental, tendo como fontes primárias as mensagens apresentadas pelos governadores do Estado de Goiás à Assembléia Legislativa e a legislação educacional produzida no período em apreço. Tais mensagens, que se encontram catalogadas no Arquivo Público do Estado de Goiás e constituem objeto dessa pesquisa, são em número de cinco, destacando o governo de Jerônimo Coimbra Bueno (1947-1950), Pedro Ludovico Teixeira (19511954), José Ludovico de Almeida (1955-1959), José Feliciano Ferreira (1959-1961) e Mauro Borges Teixeira (1961-1964).
\end{abstract}

Palavras-chave: Escola Pública. Política. Ensino Primário.

\section{DIALOGUES BETWEEN EDUCATION AND POLITICS: PRIMARY EDUCATION IN THE MESSAGES OF GOVERNORS OF GOIÁS (1946-1961)}

\begin{abstract}
The main aim of this study is to analyze the organization and structure of primary education from 1946 to 1961, based on the messages of governors of Goiás. It is a documentary qualitative research, which used as primary sources the messages sent by the governors of State of Goiás to the Legislative Assembly and the educational legislation produced in the referred period. There are five of these messages, which are catalogued in the Public Archive of the State of Goiás and are the object of this research, highlighting the government of Jerônimo Coimbra Bueno(1947-1950), Pedro Ludovico Teixeira (1951-1954), José Ludovico de Almeida (1955-1959), José Feliciano Ferreira (1959-1961) e Mauro BorgesTeixeira (1961-1964).
\end{abstract}

Key-words: Public school. Politics. Primary School. 


\section{V, 13, n. 1, 2017.}

\section{INTRODUÇÃO}

O presente estudo tem como objetivo principal analisar a organização e estrutura do ensino primário, no período de 1946 a 1961, a partir das mensagens dos governadores de Goiás. Deste modo, para a escrita deste texto foram privilegiadas, como fontes primárias, tais Mensagens, produzidas neste período. A análise desta documentação oportunizou a percepção das falas político-oficiais nos mais variados campos da ação do Estado, permitindo a identificação de elementos relevantes para a análise que se propõe desenvolver.

O teor das Mensagens se expressa pelos diversos aspectos que envolvem a administração pública: agricultura, pecuária, economia, saúde pública, educação, entre outras $^{1}$. E, para tanto, procuram realizar um balanço administrativo por parte do Poder Executivo sobre os andamentos administrativos do governo sob sua responsabilidade. Ademais,

\footnotetext{
Geralmente constituem em relatório de governo, o que envolve descrições, justificativas, balanços, prestação de contas, conclamações, apelos, avaliações, explicitação de objetivos e de anseios de ordem administrativa, bem como de projetos para o ano vindouro, podendo acenar ainda com a necessidade de projetos para um futuro menos imediato (ARAÚJO, 2012, p. 102).
}

As Mensagens, que se encontram catalogadas no Arquivo Público do Estado de Goiás e constituem objeto dessa pesquisa, são em número de cinco, destacando o governo de Jerônimo Coimbra Bueno (1947-1950), Pedro Ludovico Teixeira (1951-1954), José Ludovico de Almeida (1955-1959), José Feliciano Ferreira (1959-1961) e Mauro Borges Teixeira (1961-1964).

\section{MODERNIZAÇÃO E EDUCAÇÃO EM GOIÁS}

O estado de Goiás, até 1930, encontrava-se quase que no anonimato. Estado pobre e periférico, era visto pelos viajantes e elite brasileira como o lugar da decadência e do atraso, uma região improdutiva e pouco habitada. Morada de índios e feras, espaço habitado por sertanejos pobres, deseducados, preguiçosos e doentes.

\footnotetext{
${ }^{1}$ No entanto, para esta pesquisa, serão analisados apenas os itens relativos à educação.
} 


\section{V, 13, n. 1, 2017.}

A sociedade goiana era vista "como uma sociedade da ausência. Nada produzia, pouco consumia, era quase um ônus para o país” (PINTO, 2009, p. 49). Aliada à ideia da decadência estava a questão do isolamento, pois, "isolado das regiões mais prósperas do país, sem meios de comunicação, ferroviário e rodoviário, Goiás permaneceu até a primeira década deste século XX em quase total isolamento" (CHAUL, 2001, p. 98).

As décadas de 1930/1940 - período da criação e instalação de Goiânia representaram, para Goiás, seus primeiros passos rumos à "modernidade". Logo:

A nova cidade-capital do estado de Goiás, cidade planejada e construída sob os auspícios da modernidade arquitetônica e urbanística, surgia como ruptura com o passado decadente e atrasado e como promessa de um futuro promissor para o 'filho mais modesto, o filho menos educado' entre os filhos do pai Brasil (PINTO, 2009, p. 43).

A nova capital significou para Goiás um novo tempo. A partir de sua construção, foi possível promover a abertura de novas estradas, que se tornaram elos entre os municípios e com outros estados, favorecendo a migração e,

[...] consequentemente o povoamento, acelerando a colonização do Mato Grosso Goiano, zona de grande riqueza agrícola; criou o primeiro centro urbano de relativa importância em Goiás que, se não chegou a constituir um centro industrial - como esperavam os construtores -, desenvolveu para si e para todo o estado os diversos tipos de serviços (colégios e faculdades, bancos, hospitais, comércio, etc) indispensáveis ao desenvolvimento (PALACIN; MORAES, 1975, p. 109).

Assim como Goiânia, a construção de Brasília, na década de 1950 contribuiu para a reestruturação do espaço goiano, pois:

A construção de vias de integração nacional causaram grandes alterações, do ponto de vista espacial, no Brasil e em Goiás, contextualizando-se no momento em que o planejamento foi tido como instrumento capaz de corrigir os desequilíbrios regionais e econômicos, garantindo um contínuo processo de intervenção estatal na economia (PEREIRA, 2004, p. 34).

Sem sombra de dúvidas, a criação de Goiânia e de Brasília em território goiano representou mudanças profundas para a sociedade, tanto econômicas, quanto políticas, culturais e sociais. 


\section{V, 13, n. 1, 2017.}

Para a educação, o que significou o processo de modernização ${ }^{2}$ pelo qual passava o Estado?

\subsection{Aspectos quantitativos e qualitativos da escola primária}

No período de 1930 a 1945, a população presenciou um aumento expressivo no número de escolas públicas primárias mantidas pelo Estado. Todavia, se por um lado foram notáveis os progressos alcançados com a expansão do ensino, não foi possível, por outro, resolver alguns dos problemas mais graves, como, por exemplo, o da extensão da escola primária a toda população, que crescia em números expressivos, devido ao fluxo de migração para Goiânia, a nova capital.

Em 1950, o Estado possuía 1.682 salas de aula espalhadas por todo o seu território, enquanto, o mínimo suficiente para atender a demanda seria de 3.125 unidades $^{3}$ conforme $^{2}$ declaração do Governador do Estado Jerônimo Coimbra Bueno ${ }^{4}$ (1947-1950).

Mesmo com a oferta limitada, o dirigente político afirmava, por meio da Mensagem apresentada à Assembleia Legislativa, que o ensino primário havia atingido níveis plenamente satisfatórios:

O ensino primário tem experimentado excelentes progressos em todos os sentidos, e é possível afirmar-se hoje que atingiu a um grau plenamente satisfatório de desenvolvimento ainda que suas possibilidades estejam em verdade aquém das solicitações do Povo Goiano (GOIÁS, 1950).

A fala do líder político refere-se à construção de 49 grupos escolares em três anos de governo, pois, "foram criados, em 1949, por leis especiais, 30 novos grupos escolares e mais 19 nos anos de 1947 e 1948 [...] fato que dispensa quaisquer comentários” (GOIÁS, 1950).

No entanto, a maior defasagem de atendimento às crianças em idade escolar ${ }^{5}$ relacionava-se ao ensino rural. Segundo o governador, se nesse período fossem construídas

\footnotetext{
${ }^{2}$ Segundo Germani (1974), modernização é um processo global no qual, entretanto, é necessário distinguir uma série de processos componentes. Em cada país, a peculiaridade da transição resulta em grande parte, do fato de que a sequência, assim como a velocidade, em que ocorrem tais processos componentes variam consideravelmente de lugar para lugar, por causa das circunstâncias históricas diferentes, tanto no nível nacional, quanto no nível internacional.

${ }^{3}$ Relatório apresentado ao governador do Estado de Goiaz, Dr. Jerônimo Coimbra, pelo Dr. Hélio Seixo de Brito, Secretário de Estado da Educação (GOIÁS, 1949).

4 Jerônimo Coimbra Bueno era natural de Rio Verde. Engenheiro, foi um dos responsáveis pelas obras civis da construção de Goiânia. Em 1947, com o apoio da UDN (União Democrática Nacional), PSP (Partido Social Progressista) e uma dissidência do PSD (Partido Social Democrático), foi eleito governador de Goiás.
} 


\title{
V, 13, n. 1, 2017.
}

mais 1.000 classes, ainda assim o número seria insuficiente para reduzir o número de analfabetos do Estado. Nota-se que, de acordo com o censo de 1940, 85,4\% da população residia na zona rural.

A título de elucidação, os aspectos quantitativos de expansão do ensino primário estiveram associados à regulamentação do Fundo Nacional do Ensino Primário ${ }^{6}$, em 25 de agosto de 1945. Essa regulamentação estabelecia que $70 \%$ do auxílio federal destinado aos estados deveriam ser aplicados na construção de prédios escolares.

Assim, a aplicação do recurso aconteceu a passos lentos em Goiás, pois, de acordo com o governador Jerônimo Coimbra Bueno, até 1947 não havia nenhum prédio concluído, sendo tal empreitada fruto de seu trabalho:

\begin{abstract}
A construção de prédios escolares rurais com recurso do Fundo Nacional do Ensino Primário prossegue com os melhores resultados, já estando concluídos e entregues à serventia escolar nada menos de 94 prédios em todo Estado. Segundo os cinco convênios já firmados com a União, outros 114 prédios serão edificados em Goiás, o que representa a construção, neste Estado, de 208 prédios para escolas rurais, quando, ao iniciar-se o atual Govêrno, não havia um sequer concluído (GOIÁS, 1950).
\end{abstract}

No que tange ao sentido qualitativo do ensino, entre 15 de dezembro de 1949 e 15 de fevereiro de 1950, o governo estadual promoveu o Curso de Férias para professores primários. O evento foi custeado pelo Instituto Nacional de Estudos Pedagógicos (INEP) e o Estado auxiliou nas despesas com materiais e funcionários administrativos. O número de matrículas foi de 90 , porém apenas 72 professores receberam certificados de conclusão.

Além do Curso de Férias, outras dez professoras foram contempladas com bolsas de estudo e se deslocaram à capital da República para um curso de aperfeiçoamento no INEP. Das professoras goianas que frequentaram o curso, uma era de Tocantinópolis, uma da Cidade de Goiás, uma de Pires do Rio e as demais de Goiânia.

Com a regulamentação do Fundo Nacional do Ensino Primário, coube à União, por meio do INEP, custear as despesas relativas às construções escolares e à qualificação do

\footnotetext{
${ }_{5}^{5}$ Segundo o Regulamento do Ensino Primário do Estado de Goiás, a idade escolar seria de 7 a 14 anos. Tal legislação (Decreto $\mathrm{n}^{\circ}$ 805, de 28 de janeiro de 1949), foi estabelecida com o objetivo de atender as determinações da Lei Orgânica do Ensino Primário do Estado de Goiás (Decreto Estadual no 513, de 31 de agosto de 1946).

${ }^{6}$ A 14 de novembro de 1942 o governo federal - através do decreto no 4.958 - instituía o Fundo Nacional do Ensino Primário, 'formado pela renda proveniente dos tributos federais que para esse fim viessem a ser criados, destinado à ampliação e melhoria do sistema escolar primário em todo o país (PAIVA, 1987, p.139).
} 


\title{
V, 13, n. 1, 2017.
}

pessoal e aos Estados a manutenção do sistema de ensino. Regulamentaram-se, também, a participação das despesas educacionais no orçamento dos Estados e Municípios e foram centralizadas as informações sobre o ensino elementar.

Pedro Ludovico Teixeira (1951-1954) volta ao Governo do Estado $^{7}$ e com ele a vontade política de destacar seus feitos e acobertar o seu antecessor Jerônimo Coimbra Bueno, eleito pela UDN partido de oposição ao seu PSD. Assim, em Mensagem dirigida ao Legislativo, o dirigente goiano fez questão de ressaltar a situação em que se encontravam as construções dos grupos escolares financiados pelos recursos do Fundo Nacional de Ensino Primário. Dessa forma:

\begin{abstract}
Mediante inspeção feita por fiscais do Ministério da Educação e Saúde em prédios escolares rurais construídos no govêrno passado, foram verificadas graves falhas na construção dos mesmos: péssima qualidade de material empregado, desobediência às plantas estabelecidas pelo I.N.E.P., má localização das referidas escolas (várias dessas escolas foram distribuídas em fazendas despovoadas, na sua maioria de propriedades de seus companheiros políticos, encontrando-se, pois fechadas por falta de alunos) [...] A fiscalização referida, procedida rigorosamente, veio em resumo, demonstrar que somente $40 \%$ dos prédios "construídos" no govêrno anterior estavam regularmente prontos de conformidade com o que exige o Instituto Nacional de Estudos Pedagógicos (GOIÁS, 1952).
\end{abstract}

Não se pode afirmar que as declarações do governador sejam verídicas ou não, porém, se de fato ocorreu o destacado por ele, aconteceu, em Goiás, o que, na época, já era comum em outros locais, ou seja:

Ocorreu a localização dos prédios escolares como consequência das interfaces do poder político local na sua distribuição. Em muitos lugares, o desperdício de recursos chegou a ser total, com escolas construídas em regiões de população rarefeita onde era impossível o seu funcionamento por falta de professores e de alunos, servindo a construção - algumas vezes - como estábulo (PAIVA, 1987, p. 149).

Todavia, não se pode deixar de mencionar certa discrepância nas informações dos governadores. Jerônimo Coimbra Bueno, na Mensagem de 1950, afirmou que o Estado possuía 1.000 escolas isoladas. Pedro Ludovico Teixeira, na Mensagem de 1952, afirmou que "presentemente, o número de escolas se eleva a mil e trezentas (1.300), das quais trezentas (300) foram criadas em nosso primeiro ano de Govêrno" (GOIÁS, 1952).

\footnotetext{
${ }^{7}$ Pedro Ludovico Teixeira estivera à frente do Executivo estadual de Goiás de 1930 a 1945.
} 


\section{V, 13, n. 1, 2017.}

Assim, se o governador Jerônimo Coimbra Bueno concluiu apenas $40 \%$ dos grupos escolares rurais financiados pelo Fundo, por que o seu sucessor considerou os 1.000 prédios declarados, acrescentando somente os 300 construídos por ele? Verdade nas declarações ou rixa política? Não faz parte do escopo desta pesquisa o julgamento desses fatos, visto que não se inserem no objetivo proposto inicialmente, qual seja: analisar a organização e estrutura do ensino primário, no período de 1946 a 1961, a partir das mensagens dos Governadores de Goiás

Merece destaque, também, o número de professoras que participaram do curso de férias promovido pelo INEP em parceria com o governo do Estado, no período de 15 de dezembro de 1949 e 15 de fevereiro de 1950. Segundo Jerônimo Coimbra Bueno, receberam certificado final 72 professores primários. Se considerarmos os 970 professores primários do Estado em 1952, o percentual de participação foi ínfimo, limitando-se a 7,4\%.

Retoma-se a questão da formação dos professores, pois essa persistia em ser um problema vivenciado pela educação do Estado. Mesmo com um contingente de 970 professores primários, o número ainda era insuficiente para atender às necessidades. Segundo Pedro Ludovico Teixeira, existiam trinta grupos escolares criados, mas, devido à falta de professores, somente três estavam instalados. Assim, em 1952, Goiás dispunha de:

110 grupos escolares em funcionamento

3 grupos escolares instalados, sem professores

27 grupos não instalados, por falta de professores na carreira respectiva 140 grupos no total (GOIÁS, 1952).

Os dados aqui apresentados causam outra inquietação: como é possível não haver professores, se o Regulamento do Ensino Primário de Goiás não exigia a presença exclusiva de normalistas nos grupos escolares? Esses 30 grupos foram realmente construídos?

Segundo Pedro Ludovico Teixeira, o Curso de Férias, sediado em Anápolis, funcionou com regularidade e real proveito, porém não descreve o quantitativo de professores que participaram da formação.

De acordo com o livro "Goiás: limiar de um novo mundo", publicado em homenagem ao terceiro ano de mandato de José Ludovico de Almeida ${ }^{8}$ (1955-1959), até o ano de 1957, o governo já teria construído trinta e oito grupos escolares e reconstruídos dois.

\footnotetext{
${ }^{8}$ Primo de Pedro Ludovico Teixeira foi chamado pelo interventor, em 1940, para ocupar a Secretaria da Fazenda do Estado. Foi escolhido em 1946 para disputar o governo, na volta ao regime constitucional, nas eleições de
} 


\section{V, 13, n. 1, 2017.}

O tamanho dos edifícios variou em conformidade com o tamanho dos municípios, “desde os de 2 até os de 10 salas, predominando o número de estabelecimentos com 5 salas de aulas" (GOIÁS, 1957). Assim, as unidades de maior porte se encontravam em Goiânia: Grupo Escolar Padrão, com capacidade para 400 alunos e Grupo Escolar de Aplicação de Goiânia, com capacidade para 640 alunos (idem).

Segundo o governador, nesse período, foram dispensados Cr\$ 6.391.998,00 (Seis milhões, trezentos e noventa e um mil, novecentos e noventa e oito cruzeiros) em auxílio aos municípios goianos, destinados à construção, reformas e reparos de prédios escolares.

No que tange à formação dos professores, em julho de 1956, a Secretaria da Educação e Cultura fundou o Curso de aperfeiçoamento de Diretores de Ensino Primário. Percebe-se um deslocamento no que se refere à formação dos profissionais da educação, que passa do professor para o diretor dos Grupos Escolares.

José Feliciano Ferreira ${ }^{9}$ (1959-1961), em mensagem dirigida à Assembleia Legislativa, ao final de onze meses de trabalho, expõe os seus objetivos para a conclusão mandato, assim como aponta a situação da educação no Estado. Deste modo começa o governador: "Será objetivo nosso ampliar a rêde escolar primária do Estado e de particulares, propiciando meios ao crescimento da matrícula, para que o ensino de base atinja os seus objetivos de informação das massas populares" (GOIÁS, 1959).

Segundo José Feliciano Ferreira existiam, em Goiás, duzentas mil crianças em idade escolar fora da escola. Além do número elevado de crianças sem atendimento escolar, outros problemas a serem enfrentados pelo governo seriam a questão financeira e a preparação técnica de professores, em quantidade e qualidade suficientes, pois, de 2.552 professores primários, apenas 802 eram normalistas.

Merece atenção o fato de as mensagens dos governadores apresentarem dados tão discrepantes em relação ao quantitativo de professores primários do Estado. Segundo Pedro Ludovico Teixeira, em 1952 Goiás possuía 970 professores. No entanto, José Feliciano Ferreira afirma que em 1959 esse número era de 2.552, ou seja, houve um crescimento de

janeiro de 1947, pelo PSD, mas foi derrotado por Jerônimo Coimbra Bueno. Na administração de Pedro Ludovico, entre 1951 e 1954, volta à Secretaria da Fazenda. Como governador de Goiás, colaborou firmemente para a construção de Brasília e iniciou a implantação da usina de Cachoeira Dourada.

${ }^{9}$ Natural de Jataí - município do Sudoeste do Estado, - em 1947 iniciou sua carreira política como vereador sua cidade natal. Em 1950, elegeu-se Deputado estadual, foi líder da maioria e presidente da Assembleia Legislativa. Assumiu a Secretaria de Educação no governo José Ludovico e disputou o governo do Estado em 1958, vencendo César da Cunha Bastos. 


\section{V, 13, n. 1, 2017.}

160\%. Assim, cabe-nos uma dúvida: o aumento expressivo no número de professores não teria garantido uma expansão no número de classes e, logo, no número de crianças atendidas?

De acordo com José Feliciano Ferreira, em 1958, possuía o Estado 155 Grupos Escolares, 200 Escolas Reunidas e 897 Escolas Isoladas, número insuficiente para atender a população infantil escolar, que aumentava cada vez mais, em função dos fluxos migratórios encadeados pelas construções de Goiânia e Brasília. Nesse sentido, vale ressaltar que:

\section{A imigração, durante a década de 1940-1950, também alcançou um elevado índice, $1,67 \%$, que determinou, somado ao aumento vegetativo, um crescimento global da população de 3,9\% anual. De 826.414 habitantes em 1940, o Estado passou a 1.214.921 em 1950 (PALACIN; MORAES, 1975, p. 114).}

Mauro Borges Teixeira ${ }^{10}$ (1961-1964), ao assumir o governo, assim como seu antecessor, apresentou como um dos grandes problemas da educação no Estado a falta de formação dos professores. Para tanto, somente a partir de 1962 dá início ao Plano de Desenvolvimento do Estado, elaborado durante sua campanha eleitoral, o qual inclui medidas a favor da educação pública.

Não serão detalhados os empreendimentos educacionais dessa gestão, uma vez que ultrapassam o recorte temporal desta pesquisa, que se estende de 1946 a 1961. Todavia, a fim de erradicar o analfabetismo no Estado, o governo propôs a expansão da rede escolar e, por meio da formação dos professores e supervisores escolares, buscava a melhoria do nível pedagógico das escolas.

Pelo exposto até o momento, nota-se uma expansão considerável no número de escolas mantidas pelo Estado, como se ilustra na tabela abaixo:

TABELA 1 - Estabelecimentos de ensino primário mantidos pelo Estado de Goiás (19451958)

\begin{tabular}{l|l|l}
\hline Ano & Grupos Escolares & Escolas Isoladas \\
\hline 1945 & 74 & -- \\
1950 & 90 & 1.000 \\
1952 & 110 & 1.300 \\
1958 & 155 & $897 *$ \\
\hline
\end{tabular}

${ }^{10}$ Natural de Rio Verde e filho de Pedro Ludovico Teixeira, foi integrante da Comissão de Legislação da Nova Capital, eleito Deputado Federal em 1958 e governador do Estado em 1960. 


\section{V, 13, n. 1, 2017.}

Fonte: GOIÁS $(1950,1952,1958)$

* O Governador faz referência a 897 Escolas Isoladas, porém, menciona a existência de, além destas, 200 Escolas Reunidas (GOIÁS, 1958).

Em relação à Tabela 1, algumas observações são necessárias. Houve um aumento de 81 Grupos Escolares no período compreendido entre os anos de 1945 e 1958, o que representa um percentual de 109,4\%. Nota-se, também, que o crescimento destes estabelecimentos de ensino foi gradativo e não houve declínio em nenhum momento. No que tange às escolas isoladas, verifica-se um acréscimo de $30 \%$ entre os anos de 1950 e 1952 e um decréscimo de 44,9\% se comparados os períodos de 1952 e 1958.

De acordo com o Regulamento do Ensino Primário de 1949, as escolas isoladas seriam instaladas em toda a localidade em que houvesse, no mínimo, 40 crianças em idade escolar, ou seja, entre 7 e 14 anos. Para a instalação dos grupos escolares o que se exigia era a frequência mínima de 170 crianças, também em idade escolar. Logo, as escolas isoladas foram instaladas, em sua grande maioria, nas áreas rurais e os grupos escolares, nas áreas urbanas.

A construção de Goiânia, a Campanha Nacional Marcha para o Oeste e a construção de Brasília aceleraram o crescimento de Goiás entre os anos de 1940 e 1960. Nesse período houve uma ampliação considerável da população urbana em detrimento da população rural, como evidencia a Tabela 2. No entanto, a população rural continuava maior que a urbana o que pressionava o governo estadual a construir escolas isoladas nestas localidades, desde que houvesse número de alunos suficiente. Com esta medida tentava conter o êxodo rural e diminuir o número de analfabetos.

No ano de 1958 houve um decréscimo no numero de escolas isoladas. No entanto, há que se considerar que o Governador, em sua mensagem, separa as escolas isoladas das escolas reunidas, o que não ocorreu nas mensagens anteriores. Se acoplarmos os dois modelos de estabelecimento de ensino tem-se um total de 1.197, número pouco menor que o de 1952. Verifica-se, também, que de 1952 a 1958 foram construídos 52 grupos escolares. Logo, deduz-se que, como a população se urbanizava, carecia de mais investimento neste modelo de instituição escolar, que representava o que existia de mais moderno em educação.

TABELA 2 - Crescimento populacional de Goiás, por zona, entre 1940 e 1960 


\begin{tabular}{l|l|l|l|l|l|l|l|l}
\hline \multirow{2}{*}{ Vn, 13, n. 1, 2017. } & \multicolumn{3}{c}{ Zona Rural } & \multicolumn{3}{c}{ Zona Urbana } & \multicolumn{3}{c}{ Total } \\
\cline { 2 - 10 } & População & Índice & & População & Índice & & População & Índice \\
\hline 1940 & 705.758 & 100 & 85 & 120.656 & 100 & 15 & 826.414 & 100 \\
\hline 1950 & 969.254 & 137 & 80 & 245.667 & 204 & 20 & 1.214 .921 & 147 \\
\hline 1960 & 1.335 .808 & 188 & 68 & 576.359 & 477 & 32 & 1.912 .167 & 231 \\
\hline
\end{tabular}

Fonte: BRASIL. Recenseamento de 1940, 1950 e 1960.

Vê-se, pelos dados, que a população total do Estado mais que dobrou em 20 anos, tendo sido mais acentuado o seu crescimento a contar de 1950. O ritmo do crescimento da população urbana foi muito mais intenso do que o ritmo do crescimento da população total e mais ainda do que o da população rural. Observa-se que a população urbana cresceu $477 \%$ no período de 1940 a 1960, enquanto a população rural acendeu em 188\% e a população total do Estado obteve um crescimento de $231 \%$. Isso significa um procedimento de intensificação do processo de urbanização, devido, entre outros fatores, à criação de Goiânia (entre 1930 e 1940) e à construção de Brasília, que começou a ser edificada em 1956 e que atraiu milhares de migrantes.

Todavia, a "modernidade" trazida pela construção das duas capitais, pouco alterou, de imediato, a questão da educação, pois o índice de analfabetismo continuava alto. Em 1940, 80,86\% da população do Estado eram analfabetas e em 1950, 71,60\%. Apesar do aumento no percentual de pessoas alfabetizadas, Goiás estava entre os estados brasileiros com maior índice de analfabetismo.

\section{CONSIDERAÇÕES FINAIS}

Em linhas gerais, por meio desta investigação foi possível observar, nas mensagens dos gestores, que existia a preocupação em organizar o ensino primário, porém, as medidas necessárias sempre estiveram articuladas com os interesses e necessidades políticas e econômicas de cada momento conjuntural que ia se configurando.

Assim, pode-se afirmar que a expansão do sistema educacional em Goiás foi grande, mas ficou também evidente que essa expansão não foi suficiente para atingir a população em idade própria para receber educação, ou seja, crianças de 7 a 14 anos, como definido pelo Regulamento do Ensino Primário de Goiás. 


\section{V, 13, n. 1, 2017.}

No que diz respeito aos aspectos qualitativos, as mudanças no sistema educacional goiano quase não existiram. O Estado permaneceu com um grande número de professores leigos, as escolas não funcionavam em locais adequados e a base pedagógica pautava-se nos modelos tradicionais propostos pelo Regulamento, que vigorou como única legislação no período de 1949 a 1961.

Finalmente, os resultados apresentados estão ancorados no pressuposto de que todo conhecimento histórico tem a dimensão de provisoriedade e de limitação, permitindo, assim, novas sínteses vindouras. 
V, 13, n. 1, 2017.

\section{REFERENCIAS}

ARAÚJO, José Carlos Souza. Republicanismo e escola primária nas mensagens dos presidentes de estado de Minas Gerais (1891-1930). In: ARAÚJO, José Carlos Souza; SOUZA, Rosa Fátima de; PINTO, Rubia-Mar Nunes (Org.). Escola primária na Primeira República (1889-1930): subsídios para uma história comparada. Araraquara, SP: Junqueira\&Marin, 2012.

BRASIL. Instituto Brasileiro de Geografia e Estatística. Censo Demográfico do Estado de Goiás. Série regional. Volume XXX. Tomos 1 e 2. Rio de Janeiro, 1956.

Instituto Brasileiro de Geografia e Estatística. Censo Demográfico de 1960. Série regional. Volume I. Tomo XVIII - Goiás [S.n.t].

Instituto Brasileiro de Geografia e Estatística. Recenseamento Geral do Brasil (1º de setembro de 1940). Série regional. Parte XXI - Goiaz. Rio de Janeiro, 1952.

CHAUL, Nars Fayad. Caminhos de Goiás: da construção da decadência aos limites da modernidade. 2.ed. Goiânia: Editora da UFG, 2001.

GERMANI, Gino. Sociologia da modernização. São Paulo: Mestre Jou, 1974.

GOIÁS. Goiás: Limiar de um novo mundo. Goiânia: [s.n], 1958.

Mensagem dirigida pelo Governador do Estado Jerônimo Coimbra Bueno à Assembleia Legislativa de Goiás em sua $1^{a}$ sessão ordinária no ano de 1950. Goiânia: Diário Oficial do Estado de Goiaz, 1950.

Mensagem dirigida pelo Governador do Estado José Feliciano Ferreira à Assembleia Legislativa no ano de 1959. Goiânia, 1959.

Mensagem dirigida pelo Governador do Estado Pedro Ludovico Teixeira à Assembleia Legislativa de Goiás no ano de 1952. Goiânia: Diário Oficial do Estado de Goiaz, 1952.

Proposta orçamentária para o ano de 1958. Goiânia, 1957.

Regulamento do Ensino Primário do Estado de Goiaz. Goiânia: Diário Oficial do Estado de Goiaz, 1949

Relatório apresentado ao governador do Estado de Goiaz, Dr. Jerônimo Coimbra Bueno, pelo Dr. Hélio seixo de brito, Secretário de Estado da Educação. Revista de Educação, Goiânia, n. 33-34, jan./ fev, 1949.

NEPOMUCENO, Maria de Araújo. A ilusão pedagógica (1930-1945): estado, sociedade e educação em Goiás. Goiânia: Editora da UFG, 1994. 


\section{V, 13, n. 1, 2017.}

PAIVA, Vanilda Pereira de. Educação popular e educação de adultos. São Paulo: Loyola, 1987.

PALACIN, Luis; MORAES, Maria Augusta de Sant'Anna (1975). História de Goiás (17221972). Goiânia: UFG, 1975.

PEREIRA, Edna Lemes Martins. Modernização e expansão do ensino em Porangatu na década de 1950. 146 f. Dissertação (Mestrado em Educação) - Faculdade de Educação, Universidade Católica de Goiás, Goiânia, 2004.

PINTO, Rubia-Mar Nunes. Goiânia, no 'Coração do Brasil' (1937-1945): a cidade e a escola reinventando a nação. 364 f. Tese (Doutorado em Educação) - Faculdade de Educação, Universidade Federal Fluminense, Niterói, 2009. 